\title{
The Effects of Dyslipidemia in Subclinical Hypothyroidism
}

Azhar Hussain $^{1}$, Abdelfatah M. Elmahdawi ${ }^{2,3}$, Noor El-Hudda Elzeraidi ${ }^{2}$, Fatimah Nouh ${ }^{4}$, Khalid Algathafi ${ }^{4}$

1. Medicine, Xavier University School of Medicine, Oranjestad, ABW 2. Lab Medicine, Higher Institute of Medical Professions, Benghazi, LBY 3. Lab Medicine, Night Institute of Medical Professions, Benghazi, LBY 4. Biochemistry, Faculty of Medicine, University of Benghazi, Benghazi, LBY

Corresponding author: Azhar Hussain, azharhu786@gmail.com

\section{Abstract \\ Background}

Subclinical hypothyroidism (SCH) affects 7.5-8.5\% of women and 2.8-4.4\% of men globally. Usually, both hypothyroidism and hyperthyroidism are related to cardiovascular and cerebrovascular disease development. The relationship between subclinical hypothyroidism and dyslipidemia has been widely investigated, but the findings remain controversial. Recent evidence shows that serum thyroxine (T4) replacement therapy may improve lipid profiles. The objective of the present study is to assess dyslipidemia among patients with SCH in Benghazi, Libya and compare it with controls.

\section{Methods}

The study was conducted from August 2018 to November 2018 and included 36 patients with SCH. All the patients were around 30 years of age. We also included sex-matched healthy subjects (controls) selected from three diabetes and endocrinology clinics in Benghazi: Alhaya clinic, Alrazy clinic, and Alnukbah clinic. Clinical information and medical history were obtained through a questionnaire from all SCH patients and normal control subjects. Blood samples were collected and analyzed for thyroid-stimulating hormone (TSH), free thyroxine (FT4), total cholesterol (T-Chol), serum triglycerides (STG), low-density lipoproteincholesterol (LDL-C), and high-density lipoprotein-cholesterol (HDL-C).

\section{Results}

Patients with SCH showed significantly higher T-Chol, STG, and LDL-C levels, as well as significantly lower levels of HDL-C in comparison to the healthy controls. No significant correlation was found between TSH and T-Chol, STG, HDL-C, and LDL-C; no significant correlation was found between FT4 and HDL-C either. However, a strong negative correlation was found between FT4 and T-Chol, STG, and LDL-C.

Received 11/06/2019

Review began 11/12/2019 Review ended 11/12/2019 Published 11/16/2019

\section{๑) Copyright 2019}

Hussain et al. This is an open access article distributed under the terms of the Creative Commons Attribution License CC-BY 3.0., which permits unrestricted use, distribution, and reproduction in any medium, provided the original author and source are credited.

\section{Conclusion}

Our study concluded that SCH is associated with dyslipidemia. We strongly recommend biochemical screening for thyroid dysfunction for all patients with dyslipidemia.

Categories: Endocrinology/Diabetes/Metabolism, Family/General Practice, Internal Medicine Keywords: dyslipidemia, low-density lipoprotein cholesterol, subclinical hypothyroidism, thyroid stimulating hormone (tsh), total cholestrol

\section{Introduction}

Subclinical hypothyroidism (SCH) is characterized by high levels of serum thyroid-stimulating hormone (TSH) along with normal levels of serum thyroxine (T4) and triiodothyronine (T3) with few or no signs/symptoms of hypothyroidism [1]. The discussions about the management of subclinical thyroid dysfunction have been controversial. The prevalence of $\mathrm{SCH}$ is about $4-8.5 \%$ globally and maybe as high as $20 \%$ in women older than the age of 60 years [2]. There is good evidence that SCH can often progress to overt disease. SCH is a strong indicator of the risk for atherosclerosis and myocardial infarction in elderly women [3]. SCH is associated not only with elevated low-density lipoprotein-cholesterol (LDL-C) levels and low high-density lipoprotein-cholesterol (HDL-C) levels but also with elevated lipoprotein(a). This may further increase the risk of the development of atherosclerosis [4].

\section{Materials And Methods}

\section{Subjects}

The study was conducted from August 2018 to November 2018 and included 36 patients with SCH. All the patients were around 30 years of age. We also included sex-matched healthy subjects (controls) selected 
from three diabetes and endocrinology clinics in Benghazi: Alhaya clinic, Alrazy clinic, and Alnukbah clinic. Patients suffering from any disease other than SCH that could affect their metabolic status and the parameters studied, such as previous or family history of thyroid disorders, malignancy, liver disease, kidney disease, acute or chronic inflammation, recent surgery, diabetes, or any disease that could affect patient lipid profiles were excluded from the study. Pregnant and lactating women were also excluded.

\section{Methods}

The tests for total cholesterol (T-Chol), serum triglycerides (STG), HDL-C, and LDL-C were done using the standard procedures and available commercial kits in a fully automated system, COBAS INTEGRA 400 plus (Roche, Germany). TSH and free thyroxine (FT4) were measured using COBAS e 411 (Roche, Germany) by electrochemiluminescence technique.

\section{Statistical Analysis}

The data were analyzed using the statistical package for the social sciences (SPSS) Windows version 17 (IBM, Armonk, NY). Descriptive characteristics of the study participants were calculated as mean $( \pm)$ standard deviation (SD). An independent sample t-test was used to determine the differences in subject characteristics. Pearson's correlation coefficient determination was done to evaluate the degree of association between thyroid function changes and clinical and biochemical parameters. A p-value (twotailed) of $<0.05$ was considered as statistically significant.

\section{Results}

The mean age and SD of SCH patients selected for this study were [42.8 $( \pm 13.4)]$, and the male-to-female ratio was 13:23. The age range was $19-63$ years. The mean age and SD of the healthy control subjects were [44.8 ( \pm 12.0$)]$, and the male-to-female ratio was $12: 18$. The age range was $24-68$ years.

The mean of TSH was significantly higher in SCH patients $[13.60( \pm 11.81) \mathrm{mIU} / \mathrm{L}]$ when compared to normal controls $[2.03( \pm 0.65) \mathrm{mIU} / \mathrm{L}]$ (p: 0.00). The FT4 mean concentration was significantly lower in SCH [12.91 $( \pm 2.61) \mathrm{ng} / \mathrm{dl}]$ than normal healthy controls $[16.20( \pm 1.21) \mathrm{ng} / \mathrm{dl}]$ (p: 0.00). The level of T-Chol was even markedly higher in SCH patients $[215.08( \pm 38.75) \mathrm{mg} / \mathrm{dl}]$ than in normal healthy controls $[174.50( \pm 29.15)$ $\mathrm{mg} / \mathrm{dl}]$ (p: 0.00). The mean level of STG was significantly higher in SCH patients $[153.58( \pm 50.86) \mathrm{mg} / \mathrm{dl}]$ when compared to normal healthy controls $[130.26( \pm 40.74) \mathrm{mg} / \mathrm{dl}]$ (p: 0.00). However, the mean level of HDL-C was significantly lower in SCH patients $[25.83( \pm 6.86) \mathrm{mg} / \mathrm{dl}]$ when compared to normal healthy controls $[37.86( \pm 3.96) \mathrm{mg} / \mathrm{dl}]$ (p: 0.00). The mean level of LDL-C was significantly higher in SCH patients $[129.97( \pm 20.97) \mathrm{mg} / \mathrm{dl}]$ in contrast to normal healthy controls $[89.93( \pm 10.45) \mathrm{mg} / \mathrm{dl}]$ (p: 0.00). All relevant parameters are laid out in Table 1.

\begin{tabular}{|c|c|c|c|}
\hline Parameters & SCH patients, $n=36$ & Controls, $\mathrm{n}=\mathbf{3 0}$ & P-value \\
\hline TSH, mlU/L & $13.60( \pm 11.81)^{*}$ & $2.03( \pm 0.65)^{\star}$ & 0.00 \\
\hline FT4, ng/dl & $12.91( \pm 2.61)^{\star}$ & $16.20( \pm 1.21)^{\star}$ & 0.00 \\
\hline T-Chol, mg/dl & $215.08( \pm 38.75)^{\star}$ & $174.50( \pm 29.15)^{\star}$ & 0.00 \\
\hline STG, mg/dl & $153.58( \pm 50.86)^{\star}$ & $130.26( \pm 40.74)^{\star}$ & 0.00 \\
\hline HDL-C, mg/dl & $25.83( \pm 6.86)^{\star}$ & $37.86( \pm 3.96)^{\star}$ & 0.00 \\
\hline LDL-C, mg/dl & $129.97( \pm 20.97)^{\star}$ & $89.93( \pm 10.45)^{\star}$ & 0.00 \\
\hline
\end{tabular}

TABLE 1: Comparison of parameters between subclinical hypothyroidism patients and the control group

SCH: subclinical hypothyroidism; n: number; TSH: thyroid-stimulating hormone; FT4: free thyroxine; T-Chol: total cholesterol; STG: serum triglycerides; HDL-C: high-density lipoprotein-cholesterol; LDL-C: low-density lipoprotein-cholesterol

${ }^{*}$ Figures in parentheses represent standard deviation

There was no significant correlation between TSH and T-Chol, STG, HDL-C, and LDL-C. And no significant correlation was found between FT4 and HDL-C. However, there was significant negative correlation between FT4 and T-Chol (p: 0.044, r: -0.337) (Figure 1), STG (p: 0.044, r: -0.338) (Figure 2) and LDL-C (p: 0.049, r: 0.330) (Figure 3). 


\section{Cureus}

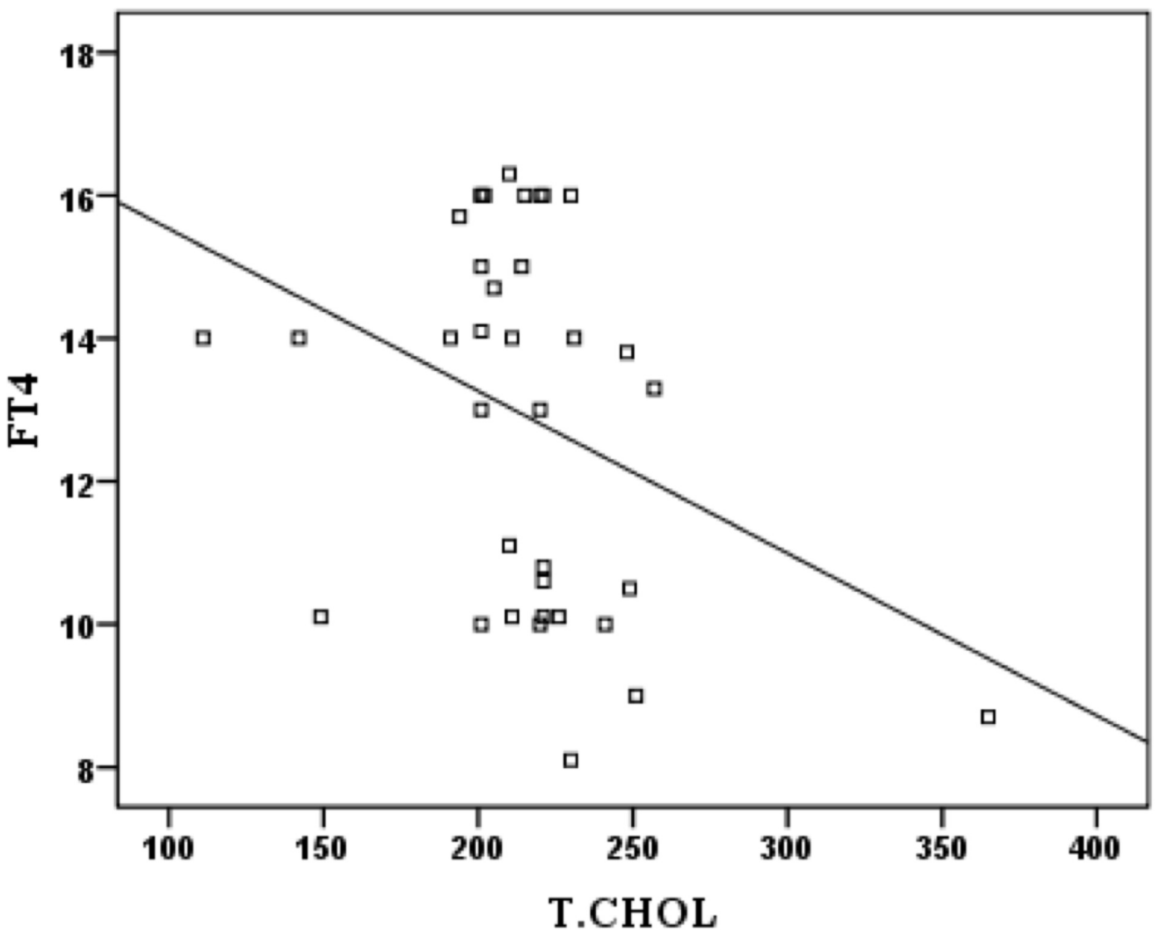

FIGURE 1: Correlation between FT4 and T-Chol in subclinical hypothyroidism patients

FT4: free thyroxine; T-Chol: total cholesterol

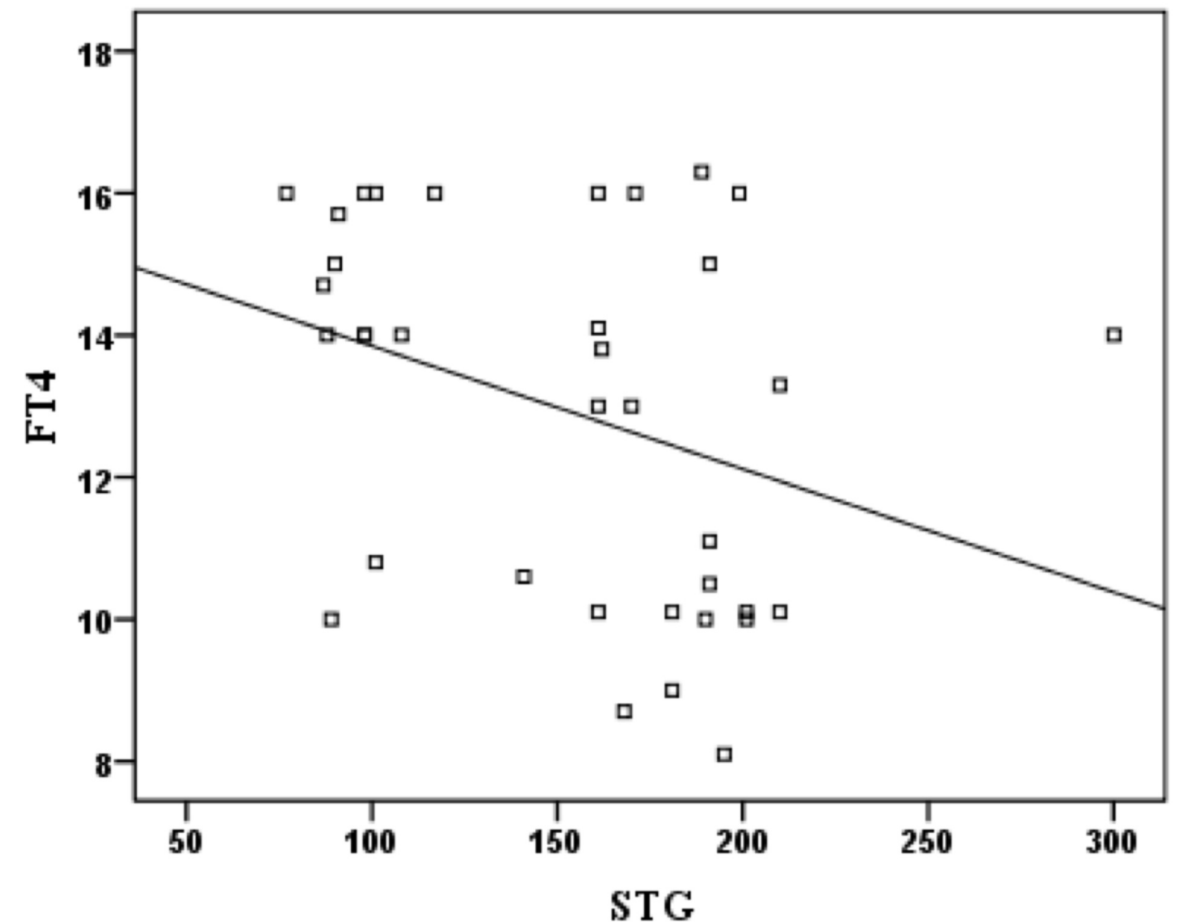

FIGURE 2: Correlation between FT4 and STG in subclinical hypothyroidism patients

FT4: free thyroxine; STG: serum triglycerides 


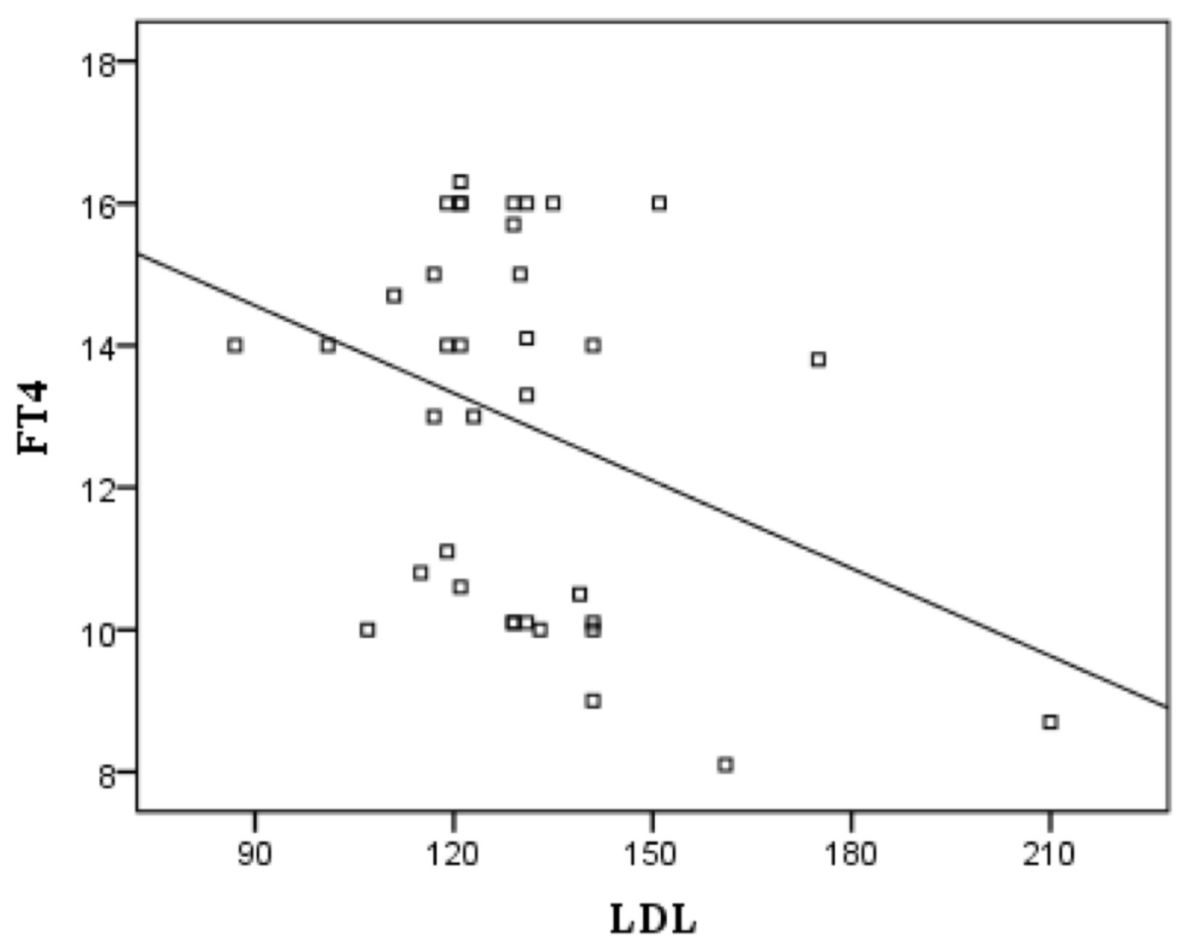

FIGURE 3: Correlation between FT4 and LDL-C in subclinical hypothyroidism patients

FT4: free thyroxine; LDL-C: low-density lipoprotein-cholesterol

\section{Discussion}

This study shows a strong connection between SCH and dyslipidemia. Dyslipidemia was more established in patients with SCH in comparison to the control group, and the levels of T-Chol, STG, and LDL-C were significantly higher among SCH patients in comparison to controls. HDL-C levels were significantly lower in SCH patients in comparison to controls. This finding is in agreement with the study by Hueston et al. as it also showed an increase in T-Chol levels in patients with SCH in contrast with the control group. But, after the reconciliation of confounding elements and the use of cholesterol-lowering drugs, no significant difference was observed between the two groups regarding the lipid profile [5]. In a study conducted by Lai et al., low levels of thyroid hormone in euthyroid patients were associated with dyslipidemia in a Chinese community [6]. A study by Luboshitzky et al. found that among the lipid profiles of SCH patients, only STG levels were higher when compared to the control group [7]. Another study conducted by Al Sayed et al. showed that T-Chol and LDL-C levels were significantly higher in patients with SCH compared to the control group [8]. However, there are many studies that did not find this positive relationship between SCH and dyslipidemia $[9,10]$, which contrasts with the results of our study.

\section{Conclusions}

In conclusion, dyslipidemia and its dangerous effects on the cardiovascular system, including diastolic dysfunction, ischemic heart disease (IHD), heart failure, and an overall increase in mortality imply that SCH is considered an atherogenic condition as it causes an increase in lipid levels and an increased risk for cardiovascular disease. Therefore, biochemical screening for thyroid dysfunction is recommended for all patients with dyslipidemia and underlying hypothyroidism. Treatment of $\mathrm{SCH}$ with thyroxine improves quality of life and decreases the risk for dyslipidemia and cardiovascular disease.

\section{Additional Information}

\section{Disclosures}

Human subjects: Consent was obtained by all participants in this study. Benghazi Medical Center issued approval 59718. The study was registered on July 9, 2018 and was approved by the institutional review board of Benghazi Medical Center. The registration number is 59718. Animal subjects: All authors have confirmed that this study did not involve animal subjects or tissue. Conflicts of interest: In compliance with the ICMJE uniform disclosure form, all authors declare the following: Payment/services info: All authors have 
declared that no financial support was received from any organization for the submitted work. Financial relationships: All authors have declared that they have no financial relationships at present or within the previous three years with any organizations that might have an interest in the submitted work. Other

relationships: All authors have declared that there are no other relationships or activities that could appear to have influenced the submitted work.

\section{References}

1. Ayala AR, Danese MD, Ladenson PW: When to treat mild hypothyroidism. Endocrinol Metab Clin North Am. 2000, 29:399-415. 10.1016/S0889-8529(05)70139-0

2. Wilson GR, Curry RW Jr: Subclinical thyroid disease . Am Fam Physician. 2005, 72:1517-24.

3. Hak AE, Pols HA, Visser TJ, Drexhage HA, Hofman A, Witteman JC: Subclinical hypothyroidism is an independent risk factor for atherosclerosis and myocardial infarction in elderly women: the Rotterdam study. Ann Intern Med. 2000, 132:270-8. 10.7326/0003-4819-132-4-200002150-00004

4. Kung AW, Pang RW, Janus ED: Elevated serum lipoprotein(a) in subclinical hypothyroidism . Clin Endocrinol (Oxf). 1995, 43:445-9. 10.1111/j.1365-2265.1995.tb02616.x

5. Hueston WJ, Pearson WS: Subclinical hypothyroidism and the risk of hypercholesterolemia . Ann Fam Med. 2004, 2:351-5. 10.1370/afm.79

6. Lai Y, Wang J, Jiang F, et al.: The relationship between serum thyrotropin and components of metabolic syndrome. Endocr J. 2011, 58:23-30. 10.1507/endocrj.k10e-272

7. Luboshitzky R, Ishay A, Herer P: Metabolic syndrome and insulin resistance in women with subclinical hypothyroidism. Endocrinol. 2010, 20:29-32. 10.1097/TEN.0b013e3181cb47da

8. Al Sayed A, Al Ali N, Bo Abbas Y, Alfadhli E: Subclinical hypothyroidism is associated with early insulin resistance in Kuwaiti women. Endocr J. 2006, 53:653-7. 10.1507/endocri.k06-018

9. Hollowell JG, Staehling NW, Flanders WD, Hannon WH, Gunter EW, Spencer CA, Braverman LE: Serum TSH, $\mathrm{T}(4)$, and thyroid antibodies in the United States population (1988 to 1994): National Health and Nutrition Examination Survey (NHANES III). J Clin Endocrinol Metab. 2002, 87:489-99. 10.1210/jcem.87.2.8182

10. Vanderpump MP, Tunbridge WM, French JM, et al.: The incidence of thyroid disorders in the community: a twenty-year follow-up of the Whickham Survey. Clin Endocrinol (Oxf). 1995, 43:55-68. 10.1111/j.13652265.1995.tb01894.x 